\title{
Is the emergency department an appropriate substitute for primary care for persons with traumatic spinal cord injury?
}

\author{
SJT Guilcher ${ }^{1,2}$, BC Craven ${ }^{1,2,3}$, A Calzavara ${ }^{4}$, MA McColl ${ }^{5,6}$ and SB Jaglal ${ }^{1,2,4,7,8}$
}

Study design: Retrospective cohort with linkage of administrative data sets.

Objectives: To describe the patterns (for example, number of visits by year post-injury) and characteristics of the emergency department (ED) visits (for example, acuity level, timing of visits, reasons for visits) made by persons with traumatic spinal cord injury (TSCl) over a 6-year period following injury.

Settings: Ontario, Canada.

Methods: Rates of ED utilization and reasons for ED visits were calculated between the fiscal years 2003-2009. Reasons for visits were categorized by acuity level: potentially preventable visits were defined as visits related to ambulatory sensitive conditions; low acuity and high acuity visits were defined by the Canadian Triage and Acuity Scale.

Results: The total number of ED visits for the 6 -year period is 4403 ( $n=1217)$. Of these visits, 752 ( $17 \%$ ) were classified as potentially preventable, 1443 (33\%) as low acuity and 2208 (50\%) as high acuity. The majority of patients, regardless of acuity level, did not see a primary care practitioner on the day of the ED visit and most visits occurred during the weekday (Mon-Fri 0700-1659 hours). ED use was highest in the first year but remained high over the subsequent years. For potentially preventable visits, the majority of visits were related to urinary tract infections ( $n=385$ visits, $51.2 \%$ ), followed by pneumonia $(n=91,12.1 \%$ ).

Conclusion: Given the high rates of ED use for low acuity and potentially preventable conditions, these results suggest that the ED is being used as an inappropriate substitute for primary care for individuals with TSCI 50\% of the time.

Spinal Cord (2013) 51, 202-208; doi:10.1038/sc.2012.123; published online 13 November 2012

Keywords: emergency department utilization; primary care; spinal cord injury

\section{INTRODUCTION}

Persons with traumatic spinal cord injury (TSCI) face numerous challenges navigating through the primary health care system. Primary care serves a vital role as the first-contact with the health system and is important for health promotion, prevention, diagnosis and treatment. ${ }^{1}$ In the general population, rates of emergency department (ED) utilization have been used as indicators of accessibility, availability and integration of primary care services. ${ }^{2}$ For persons with TSCI, the high rates of rehospitalization, ${ }^{3}$ and the frequency and severity of preventable secondary health conditions $(\mathrm{SHCs})^{4}$ suggest that there are deficiencies in care, of which insufficient primary care is presumed to be one of the key drivers.

While many of these SHCs are preventable or responsive to appropriate primary care management, ${ }^{4}$ such as urinary tract infections, pressure ulcers, pain, they are purported to be key contributors for rehospitalizations in the post-acute phase. ${ }^{3,5,6}$ The initial year post-injury has been suggested to be a critical phase in the development of $\mathrm{SHCs}^{7}$ and consequently increases the likelihood of interactions with the health care system..$^{3,5,8,9}$ In the United States, the average rehospitalization rate within the first year of injury was $55 \%$ decreasing to $37 \%$ after 5 years. ${ }^{5}$ Similarly in Canada, the frequency of $\mathrm{ED}$ and physician visits are high in this same time period. ${ }^{8}$
Thus, these SHCs may in part be due to fragmented care, and insufficient access to tertiary evaluation and primary care management. Given the relationship between ED use and primary care health services, it is important to understand the patterns of ED use over a significant period for persons with TSCI. Currently, there remains a significant gap in the literature related to examining patterns of care and characteristics of ED use in persons with SCI living in the community. The objective of this study is to describe the patterns (for example, number of visits by year post-injury) and characteristics of ED visits (for example, acuity level, timing of visits, reasons for visits) made by persons with TSCI over a 6 -year period following injury.

\section{MATERIALS AND METHODS}

\section{Setting}

A universal publicly funded health care system in the province of Ontario, with 13 million residents, representing $\sim 40 \%$ of the Canadian population.

\section{Design}

This study used a retrospective cohort design with linkage to administrative data sets. Prevalence, sociodemographics, impairment characteristics and ED

\footnotetext{
${ }^{1}$ Institute of Health, Policy, Management and Evaluation, University of Toronto, Toronto, Ontario, Canada; ${ }^{2}$ Toronto Rehabilitation Institute, University Health Network, Toronto, Ontario, Canada; ${ }^{3}$ Department of Medicine, University of Toronto, Toronto, Ontario, Canada; ${ }^{4}$ Institute for Clinical Evaluative Sciences, Toronto, Ontario, Canada; ${ }^{5}$ Centre for Health Services and Policy Research, Queen's University, Kingston, Ontario, Canada; ' ${ }^{6}$ epartment of Community Health and Epidemiology and School of Rehabilitation Therapy, Queen's University, Kingston, Ontario, Canada; ${ }^{7}$ Department of Physical Therapy, University of Toronto, Toronto, Ontario, Canada and ${ }^{8}$ Graduate Department of Rehabilitation Science, University of Toronto, Toronto, Canada

Correspondence: Dr SJT Guilcher, Department of Physical Therapy, 160-500 University Avenue, Toronto, Ontario, Canada M5G 1V7.

E-mail: sara.guilcher@utoronto.ca
}

Received 5 March 2012; revised 17 September 2012; accepted 18 September 2012; published online 13 November 2012 
patterns of Ontarians with TSCI were examined and compared for the fiscal years 2003/2004 to 2008/2009 (1 April 2003 to 31 March 2009).

\section{Privacy/ethics}

This study was approved by the institutional Research Ethics Board.

\section{Data sources}

Administrative health care databases from Ontario, Canada, were used for this study and described below. Hospitalization records were obtained from the Canadian Institute for Health Information Discharge Abstract Database, which contains a detailed record of all hospital admissions from over 200 acute hospitals in Ontario. Every hospital record in the data set contains a patient's health card number, age, sex, postal code, date of admission, date of discharge and most responsible diagnostic codes (based on International Classification of Disease, Tenth Revision Canada (ICD-10-CA) codes). ${ }^{10}$ ICD-10-CA is an enhanced version of the World Health Organization's International Statistical Classification of Diseases and Related Health Problems, 10th Revision (ICD10). Outpatient physician visits were identified using the Ontario Health Insurance Plan. The main data elements included in a physician billing claim are patient and physician unique identifying number, date of the service/claim, fee code for service provided and fee paid. The Ontario Registered Persons Database contained basic demographic and vital statistics information, including death date, for each Ontario resident. The NACRS (National Ambulatory Care Resource System) database provided information on all visits to the ED and the main data elements are reasons for the ED visit and patient demographics. All databases were linked anonymously using encrypted individual health card numbers.

\section{Study population}

Individuals with TSCI admitted to Ontario hospitals between 1 April 2003 and 31 March 2009 were included in the cohort. Index cases were identified from acute care hospitalization records using ICD-10-CA diagnostic codes for SCI that have been previously used to determine TSCI incidence in Ontario. ${ }^{11}$ Records were excluded if: gender was missing, age at index admission for SCI was $<18$ years, previous hospital stay for TSCI, index admission was not classified as the main reason for admission, died within index hospital admission, discharged after 31 March 2009 or repeated admission record. ${ }^{11}$

\section{Demographic variables}

Individual level variables included the following: age, sex, income quintile, rurality, injury level (cervical, thoracic, lumbar, other), concurrent traumatic brain injury, Charlson comorbidity index Deyo-Adaption for administrative data, ${ }^{12}$ direct discharge to short-stay or long-stay rehabilitation, length of stay of index admission (admission to discharge), and whether individuals had a regular primary care physician (defined by having no primary care physician office visit or less than a rate of one per year of primary care physician office visits. The Rurality Index of Ontario (RIO) is a scaled index based on population factors and distance (ranges $0-100$ ), and communities with higher values (cut point $\geqslant 45$ ) are more rural. ${ }^{13}$ Income levels are imputed from Census data, with the Ontario population divided into income quintiles with 1 being the lowest and 5 being the highest. Individuals were determined to not have a regular primary care physician by having no primary care physician office visit or less than a rate of one per year of a primary care physician office visit.

\section{Total ED visits by year}

The number of ED visits was counted for individuals from the date of index discharge from acute care to 31 March 2009. Individuals were assigned to a 'subcohort' based on the fiscal year of their index hospitalization, but the ED visits were stratified by 1-year increments from index discharge.

\section{Visit types and characteristics}

Potentially preventable, low acuity and high acuity visits. ED visits were classified as potentially preventable, low acuity and high acuity based on previous work examining ED use among nursing home residents. ${ }^{14}$ Potentially preventable visits were defined as visits to the ED for Ambulatory Care Sensitive Conditions (ACSC), which are conditions that likely could have been managed by timely and effective primary care. ACSC are frequently used as indicators of lack of primary care access (see Appendix A). ${ }^{14-16}$ We used the ACSC codes recently used by Grunier and colleagues, ${ }^{14}$ which are based on Billings et al. ${ }^{15}$ The Canadian Triage and Acuity Scale (CTAS) was used to define low and high acuity. The CTAS is a standardized measure of urgency for care in NACRS and the CTAS is administered to all persons visiting the ED. ${ }^{17}$ Low acuity visits were defined as those visits with a CTAS score of 4 or 5 (less or non-urgent) and high acuity visits 1-3. If visits were not categorized as ACSC, these visits were then coded as either low or high acuity using the CTAS.

Visit characteristics. ED records were linked to physician billings to ascertain whether patients were seen by a physician on the day of the ED event. The timing of visit was captured by identifying the day and time of the visit: weekday (Mon-Fri 0700-1659 hours), weeknight (Mon-Fri 1700-0659 hours), weekend day (Sat, Sun 0700-1659 hours), weekend night (Sat, Sun 1700-0659 hours), and weekend (Fri 1700 to Mon 0659 hours). The most common procedure was determined by the highest percentage of all the recorded procedures performed during the visits. The 10 most-frequent reasons for ED visits were determined by the first three digits of the ICD-10-CA codes.

\section{Analysis}

There were two main analyses for this study, a longitudinal analysis that examined trends in ED use over time since injury and an aggregated analysis of all ED visits in the study period. The number of individuals per fiscal year were identified and compared on sociodemographic variables (sex, age, etiology of injury, level of injury, Charlson Index, traumatic brain injury diagnosis, discharge disposition from index acute setting, rurality, income quintile, length of acute care stay). 'Index' refers to the initial hospital admission related to the TSCI event. For each fiscal year subcohort, the following variables were calculated for every 1-year increment of follow-up data available from the index discharge date: the rate of $\mathrm{ED}$ visits (calculated by the number of visits per 100 persons), percentage of cohort with at least one visit to the ED, number of deaths and number lost to follow-up. Individuals who died or were lost to follow-up were censored, such that any ED visits during the incomplete year were not included in the ED visit count for that particular year; however, these visits of censored individuals were captured in the aggregated analysis. For example, every individual who did not die was censored at the end of the study period; that is, those who suffered their injury in 2008-2009 were censored after 1 year, and those injured in 2007-08 after 2 years, etc. We divided the follow-up into 1-year intervals from the date of index discharge, but for each individual at some point in the follow-up, there is $<1$ year between the end of the previous interval and the end of the study follow-up. We censored the individual for the incomplete interval so that all intervals are comparable.

\section{RESULTS}

\section{Demographics and clinical characteristics}

There were 1515 TSCI index cases that met our inclusion criteria and 1217 were classified as incident cases (see Appendix B). Table 1 shows the demographics and clinical characteristics of each subcohort by fiscal year as well as the overall cohort $(N=1217)$. Among the overall cohort, the majority were male $(n=912 ; 74.9 \%)$, had an injury at the cervical spine level $(n=773,63.5 \%)$, Charlson index of $0 \quad(n=796$; $65.4 \%)$, and lived in an urban setting $(n=976,80.2 \%)$. There were no major differences in any of these characteristics by fiscal year. Only 121 individuals (9.9\%) did not have a regular primary care physician.

\section{ED utilization stratified by years post-injury}

In the first year following a TSCI, the number of visits per 100 persons ranged from 88 (fiscal year 2004/2005) to 122 (fiscal year 2008/2009; see Table 2). ED visits were generally more frequent in the first year following a TSCI, regardless of the fiscal year in which the 
Table 1 Sociodemographic and clinical characteristics of TSCI, fiscal years 2003/2004 to 2008/2009

\begin{tabular}{|c|c|c|c|c|c|c|c|}
\hline Variable & $\begin{array}{c}2003 / 2004 \\
N=176\end{array}$ & $\begin{array}{c}2004 / 2005 \\
N=196\end{array}$ & $\begin{array}{c}2005 / 2006 \\
N=205\end{array}$ & $\begin{array}{c}2006 / 2007 \\
N=217\end{array}$ & $\begin{array}{c}2007 / 2008 \\
N=225\end{array}$ & $\begin{array}{c}2008 / 2009 \\
N=198\end{array}$ & $\begin{array}{c}\text { Total } \\
\mathrm{N}=1217\end{array}$ \\
\hline $\begin{array}{l}\text { Age } \\
\text { Mean } \pm \text { s.d. } \\
\text { Median (IQR) }\end{array}$ & $\begin{array}{c}48.5 \pm 19.7 \\
46(31-64)\end{array}$ & $\begin{array}{c}48.5 \pm 18.1 \\
48(35-63)\end{array}$ & $\begin{array}{c}49.7 \pm 19.2 \\
49(33-66)\end{array}$ & $\begin{array}{l}48.2 \pm 19.0 \\
47(33-63)\end{array}$ & $\begin{array}{l}51.6 \pm 19.1 \\
54(37-66)\end{array}$ & $\begin{array}{c}50.0 \pm 19.2 \\
50(36-64)\end{array}$ & $\begin{array}{c}49.5 \pm 19.1 \\
49(33-64)\end{array}$ \\
\hline $\begin{array}{l}\text { Sex } \\
\quad \text { Female } \\
\text { Male }\end{array}$ & $\begin{array}{r}45(25.6 \%) \\
131(74.4 \%)\end{array}$ & $\begin{array}{r}47(24.0 \%) \\
149(76.0 \%)\end{array}$ & $\begin{array}{r}53(25.9 \%) \\
152(74.1 \%)\end{array}$ & $\begin{array}{r}61(28.1 \%) \\
156(71.9 \%)\end{array}$ & $\begin{array}{r}49(21.8 \%) \\
176(78.2 \%)\end{array}$ & $\begin{array}{r}50(25.3 \%) \\
148(74.7 \%)\end{array}$ & $\begin{array}{l}305(25.1 \%) \\
912(74.9 \%)\end{array}$ \\
\hline $\begin{array}{l}\text { Injury level } \\
\text { Cervical SCl } \\
\text { Thoracic SCl } \\
\text { Lumbar SCl } \\
\text { Other SCl }\end{array}$ & $\begin{array}{r}110(62.5 \%) \\
36(20.5 \%) \\
22(12.5 \%) \\
8(4.5 \%)\end{array}$ & $\begin{aligned} 122 & (62.2 \%) \\
45 & (23.0 \%) \\
22 & (11.2 \%) \\
7 & (3.6 \%)\end{aligned}$ & $\begin{array}{c}132(64.4 \%) \\
53(25.9 \%) \\
17(8.3 \%) \\
\leqslant 5\end{array}$ & $\begin{aligned} & 139(64.1 \%) \\
& 49(22.6 \%) \\
& 24(11.1 \%) \\
& \leqslant 5\end{aligned}$ & $\begin{array}{r}136(60.4 \%) \\
54(24.0 \%) \\
26(11.6 \%) \\
9(4.0 \%)\end{array}$ & $\begin{array}{c}134(67.7 \%) \\
40(20.2 \%) \\
16(8.1 \%) \\
8(4.0 \%)\end{array}$ & $\begin{array}{c}773(63.5 \%) \\
277(22.8 \%) \\
127(10.4 \%) \\
40(3.3 \%)\end{array}$ \\
\hline $\begin{array}{l}\text { Charlson index } \\
0 \\
1 \\
2 \\
3+\end{array}$ & $\begin{aligned} & 125(71.0 \%) \\
& 12(6.8 \%) \\
& 27(15.3 \%) \\
& 12(6.8 \%)\end{aligned}$ & $\begin{array}{c}145(74.0 \%) \\
11(5.6 \%) \\
28(14.3 \%) \\
12(6.1 \%)\end{array}$ & $\begin{array}{c}129(62.9 \%) \\
15(7.3 \%) \\
45(22.0 \%) \\
16(7.8 \%)\end{array}$ & $\begin{array}{c}126(58.1 \%) \\
16(7.4 \%) \\
50(23.0 \%) \\
25(11.5 \%)\end{array}$ & $\begin{array}{r}133(59.1 \%) \\
25(11.1 \%) \\
47(20.9 \%) \\
20(8.9 \%)\end{array}$ & $\begin{array}{c}138(69.7 \%) \\
11(5.6 \%) \\
40(20.2 \%) \\
9(4.5 \%)\end{array}$ & $\begin{array}{c}796(65.4 \%) \\
90(7.4 \%) \\
237(19.5 \%) \\
94(7.7 \%)\end{array}$ \\
\hline $\begin{array}{l}\text { Traumatic brain injury } \\
\text { No } \\
\text { Yes }\end{array}$ & $\begin{array}{r}148(84.1 \%) \\
28(15.9 \%)\end{array}$ & $\begin{array}{r}167(85.2 \%) \\
29(14.8 \%)\end{array}$ & $\begin{array}{r}170(82.9 \%) \\
35(17.1 \%)\end{array}$ & $\begin{array}{r}178(82.0 \%) \\
39(18.0 \%)\end{array}$ & $\begin{array}{r}191(84.9 \%) \\
34(15.1 \%)\end{array}$ & $\begin{array}{r}175(88.4 \%) \\
23(11.6 \%)\end{array}$ & $\begin{array}{r}1029(84.6 \%) \\
188(15.4 \%)\end{array}$ \\
\hline $\begin{array}{l}U_{\text {Urban }}^{a} \\
\text { No } \\
\text { Yes }\end{array}$ & $\begin{array}{r}29(16.5 \%) \\
143(81.3 \%)\end{array}$ & $\begin{array}{r}33(16.8 \%) \\
161(82.1 \%)\end{array}$ & $\begin{array}{r}43(21.0 \%) \\
159(77.6 \%)\end{array}$ & $\begin{array}{r}33(15.2 \%) \\
177(81.6 \%)\end{array}$ & $\begin{array}{r}38(16.9 \%) \\
181(80.4 \%)\end{array}$ & $\begin{array}{r}36(18.2 \%) \\
155(78.3 \%)\end{array}$ & $\begin{array}{l}212(17.4 \%) \\
976(80.2 \%)\end{array}$ \\
\hline $\begin{array}{l}\text { Income quintile } \\
1=\text { Lowest; } \\
5=\text { Highest } \\
1 \\
2 \\
3 \\
4 \\
5\end{array}$ & $\begin{array}{l}43(24.4 \%) \\
39(22.2 \%) \\
27(15.3 \%) \\
37(21.0 \%) \\
29(16.5 \%)\end{array}$ & $\begin{array}{l}38(19.4 \%) \\
46(23.5 \%) \\
38(19.4 \%) \\
31(15.8 \%) \\
41(20.9 \%)\end{array}$ & $\begin{array}{l}42(20.5 \%) \\
43(21.0 \%) \\
35(17.1 \%) \\
43(21.0 \%) \\
41(20.0 \%)\end{array}$ & $\begin{array}{l}45(20.7 \%) \\
46(21.2 \%) \\
40(18.4 \%) \\
34(15.7 \%) \\
48(22.1 \%)\end{array}$ & $\begin{array}{l}47(20.9 \%) \\
51(22.7 \%) \\
46(20.4 \%) \\
42(18.7 \%) \\
38(16.9 \%)\end{array}$ & $\begin{array}{l}45(22.7 \%) \\
41(20.7 \%) \\
34(17.2 \%) \\
45(22.7 \%) \\
31(15.7 \%)\end{array}$ & $\begin{array}{l}260(21.4 \%) \\
266(21.9 \%) \\
220(18.1 \%) \\
232(19.1 \%) \\
228(18.7 \%)\end{array}$ \\
\hline $\begin{array}{l}\text { Index } L_{O S} S^{b} \\
\text { Mean } \pm \text { s.d. } \\
\text { Median (IQR) }\end{array}$ & $\begin{array}{l}18.7 \pm 18.9 \\
13(5-25)\end{array}$ & $\begin{array}{l}24.2 \pm 42.2 \\
14(6-28)\end{array}$ & $\begin{array}{l}26.3 \pm 29.7 \\
14(8-35)\end{array}$ & $\begin{array}{l}22.7 \pm 31.1 \\
14(8-27)\end{array}$ & $\begin{array}{l}22.67 \pm 28.7 \\
15(7-26)\end{array}$ & $\begin{array}{l}21.6 \pm 26.5 \\
12(6-26)\end{array}$ & $\begin{array}{l}22.8 \pm 30.4 \\
14(6-27)\end{array}$ \\
\hline $\begin{array}{l}\text { Discharge disposition } \\
\text { Home setting } \\
\text { Long-term care or complex continuing care } \\
\text { Other acute/rehab }\end{array}$ & $\begin{array}{l}61(34.7 \%) \\
\leqslant 5 \\
109(61.9 \%)\end{array}$ & $\begin{aligned} 69 & (35.2 \%) \\
6 & (3.1 \%) \\
120 & (61.2 \%)\end{aligned}$ & $\begin{array}{c}65(31.7 \%) \\
15(7.3 \%) \\
125(61.0 \%)\end{array}$ & $\begin{array}{c}59(27.2 \%) \\
19(8.8 \%) \\
138(63.6 \%)\end{array}$ & $\begin{array}{r}54(24.0 \%) \\
29(12.9 \%) \\
141(62.7 \%)\end{array}$ & $\begin{array}{c}58(29.3 \%) \\
15(7.6 \%) \\
123(62.1 \%)\end{array}$ & $\begin{array}{c}366(30.1 \%) \\
89(7.3 \%) \\
756(62.1 \%)\end{array}$ \\
\hline
\end{tabular}

Abbreviations: IQR, interquartile range; TSCI, traumatic spinal cord injury.

${ }^{a}$ Does not add to $100 \%$ due to missing data.

bIndex LOS = length of stay of index hospital admission.

injury occurred. Despite the ED visit rate being higher in the first year following injury, the ED utilization remained relatively high during the 6-year time interval. Overall, there were 110 visits per 100 persons in the first year following a TSCI, 102 visits per 100 persons in the second year, decreasing to $91,80,72$ and 99, in the third, fourth, fifth and sixth year, respectively (see Figure 1).

ED use was higher for individuals living in a rural area compared with those in more urban settings. Similar to previous results, the number of ED visits per 100 persons was highest in the first year following injury (rural-126 visits/100 persons; urban-106 visits/100 persons), and decreased slightly for the subsequent years. For example, 4 years post-injury, the number of rural visits was 109 per 100 persons, urban visits were 72 per 100 persons and 5 years postinjury, visits were 100 and 65 per 100 persons, respectfully. Similar patterns were observed in ED use over the years following injury for gender, as ED use was highest in the first year following injury but remained high over the subsequent years.

\section{Characteristics of ED visits}

The total number of ED visits between 1 April 2003 and 31 March 2009 is 4403 (Table 3). Of these visits, $752(17 \%)$ were classified as potentially preventable, $1443(33 \%)$ as low acuity and $2208(50 \%)$ as high acuity. The majority of individuals, regardless of acuity level, did not see a primary care practitioner on the day of the ED visit. Further, the largest percentage $(43.5 \%)$ of $\mathrm{ED}$ visits occurred during the weekday (Mon-Fri 0700-1659 hours). Of the procedures recorded, the most common procedures performed during the ED visit were related to X-ray imaging without contrast (thoracic cavity, abdominal cavity, spinal vertebrae). Overall, the majority of individuals were discharged home $(66.3 \%)$.

The top five reasons for ED visits by acuity are shown in Table 4. For potentially preventable visits, the majority of visits were related to urinary tract infections ( $n=385$ visits, $51.2 \%$ ), followed by pneumonia $(n=91,12.1 \%)$. Low acuity visits were mostly due to pain-related reasons ( $n=153$ visits, $10.6 \%)$, as well as prescription refills $(n=138$ visits, 9.6\%). Pain-related reasons (pain in chest or throat, abdominal and pelvic pain, dorsalgia) contributed to a significant number of high acuity visits $(n=300,13.6 \%)$.

\section{DISCUSSION}

High rates of ED visits were identified for several years following the initial TSCI. The number of visits was higher in the first year 
Table 2 Overall patterns of emergency department utilization, fiscal years 2003/2004 to 2008/2009

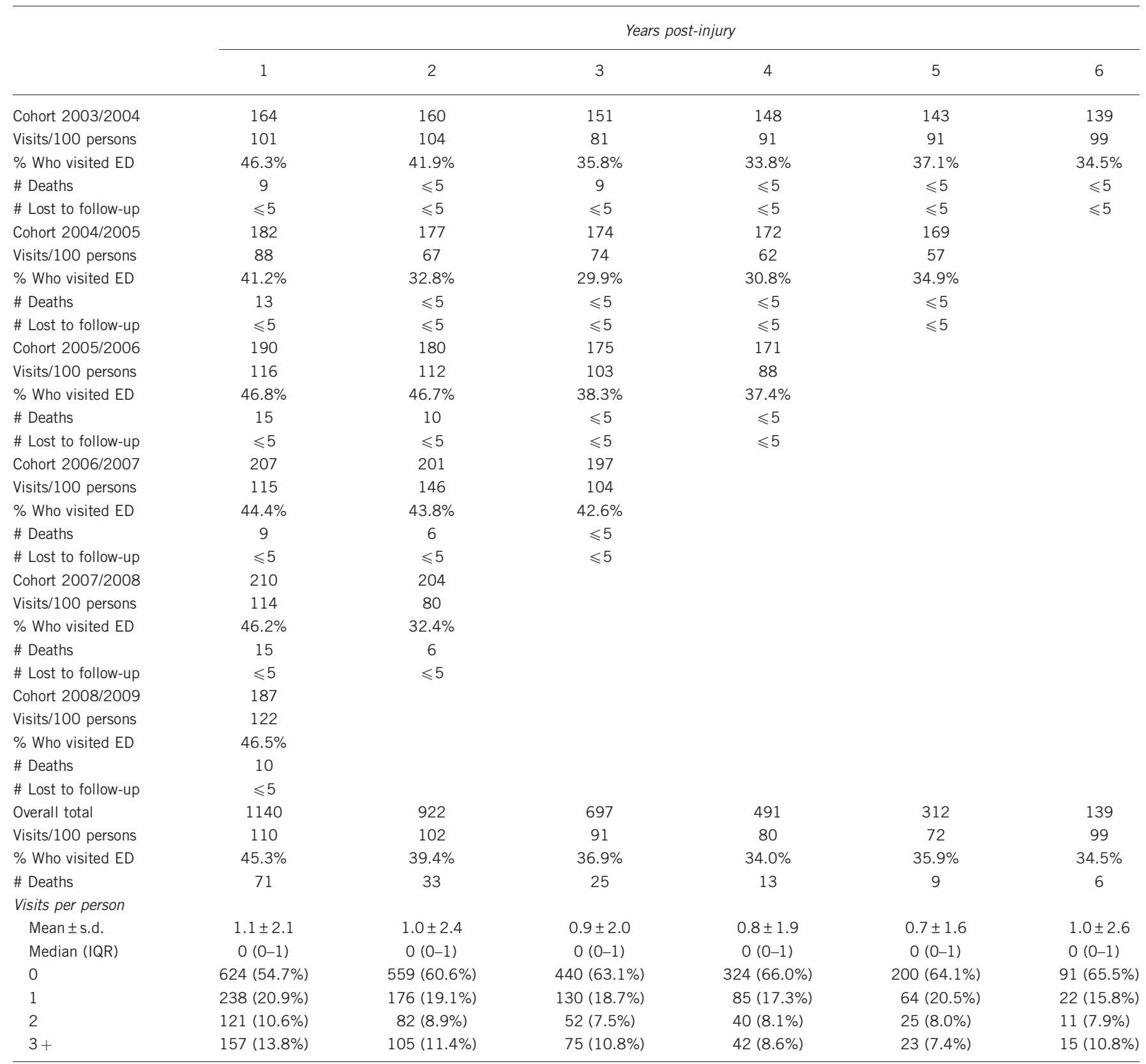

Abbreviations: ED, emergency department; IQR, interquartile range.

following injury, with 110 visits per 100 persons (45.3\% of sample visited the ED), and remained substantially high up until 6 years following injury (34.5\% of sample 6 years post-injury visited ED). High health care utilization in the first year following injury is expected but our results show that individuals are still utilizing the ED at similar high rates many years following injury. These ED rates are higher than the general population in Ontario with an average of 39.7 visits per 100 population. ${ }^{18}$ Approximately $50 \%$ of visits are emergent or urgent in nature for persons with a SCI, which are similar to the general population in Ontario, as $43 \%$ of visits classified as emergent/urgent. ${ }^{19}$

Differences in ED patterns were observed based on the rurality index, as higher ED use was noted for individuals living in rural areas compared with those in more urban settings. This finding is consistent with previous literature as access to and availability of primary care physicians is more challenged in rural than in urban centers. ${ }^{20}$ In previous work, rurality was identified as a significant predictor of ED utilization within the first year following a SCI. ${ }^{8}$ One plausible explanation is that individuals living in rural communities may not have access to a regular primary care physician. However, a recent report that examined accessibility of rural and northern communities within Ontario showed that $99.6 \%$ of those living in rural communities with populations of $\leqslant 30000$ had access to a primary care provider within a 30 -min driving distance. ${ }^{21}$

There are other barriers to accessing appropriate primary care that may include physical inaccessibility, negative attitudes of practitioners, 
lack of practitioner expertise and systemic health policies. ${ }^{22-24}$ These barriers may influence the choice of location for care. For example, if individuals need to have diagnostic imaging and/or blood work, it would be more time efficient to go to the ED for a 'one-stop shop.' For instance, referral policies to initiate services that require a physician's referral can lead to a delay in the initiation of time-sensitive services. Basic items such as prescription refills

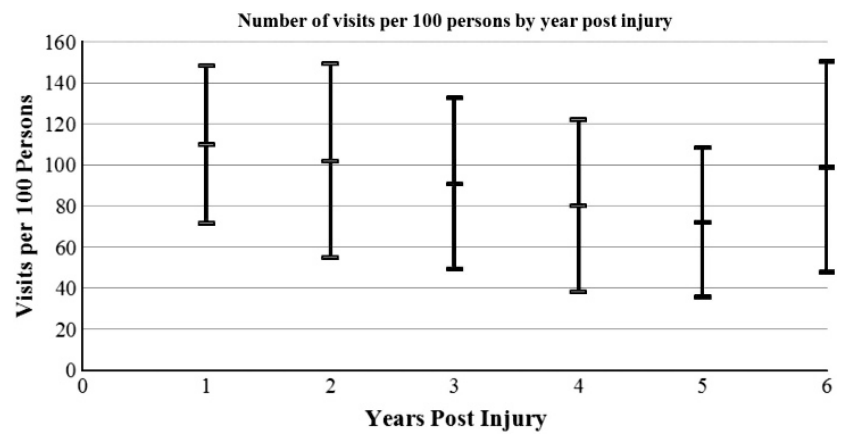

Figure 1 Emergency department (ED) visits per 100 persons by years postinjury*. *Confidence intervals are dependent on sample size and the standard deviation. The sample size progressively gets smaller with increasing years post-injury. and receiving laboratory results could be done via the telephone or video-conferencing; however, most physicians are not financially compensated unless the individual physically visits the clinic. These remuneration policies need to be modified such that persons with complex conditions are able to receive health care services with minimal inconvenience and burden.

Regardless of acuity level, most individuals did not see a primary care physician on the day of the ED visit, despite the fact that the plurality of visits occurred during the weekday working hours. Thus, for the $50 \%$ of visits classified as potentially preventable or low acuity, individuals could have accessed their primary care providers to address their health care needs rather than utilizing ED services. Furthermore, the majority of individuals (90\%) had a regular primary care physician. We have examined whether individuals saw a primary care physician on the day of the ED visit. Only $12.2 \%$ of individuals went to a general practitioner on the day of the visit. Importantly, we are unable to determine whether individuals had timely access to primary care physician. Utilizing ED services for prescription refills, for example, is not a cost-effective use of health care services. Alternately, the lack of rural diagnostic services may prompt direct ED visits. Future studies on availability of services and access are needed to understand the reasons for the current pattern or preventable or low acuity ED visits. For example, are persons going to the ED because they cannot ascertain the level of acuity at the time of decision-making?

Table 3 Characteristics of emergency department utilization, overall cohort $(N=1217)$

\begin{tabular}{|c|c|c|c|c|}
\hline \multirow[t]{4}{*}{ ED characteristic } & Potentially preventable (ambulatory & Low acuity ${ }^{a}$ & High acuity ${ }^{a}$ & \\
\hline & care sensitive conditions) & (CTAS 4-5) & (CTAS 1-3) & Total \\
\hline & $\mathrm{N}=752^{\mathrm{b}}$ & $\mathrm{N}=1443^{\mathrm{b}}$ & $\mathrm{N}=2208^{\mathrm{b}}$ & $\mathrm{N}=4403^{\mathrm{b}}$ \\
\hline & $\%(95 \% \mathrm{Cl})$ & $\%(95 \% \mathrm{Cl})$ & $\%(95 \% \mathrm{Cl})$ & $\%(95 \% \mathrm{Cl})$ \\
\hline Physician saw patient on day of ED visit (yes) & $14.0(12.5-15.4)$ & $10.4(8.8-12.0)$ & $10.4(8.2-12.6)$ & $12.2(11.2-13.2)$ \\
\hline \multicolumn{5}{|l|}{ Timing of visit } \\
\hline Weekday (Mon-Fri 0700-1659 hours) & $40.9(38.8-42.9)$ & $49.7(47.1-52.3)$ & $39.1(35.6-42.6)$ & $43.5(42.0-44.9)$ \\
\hline Weeknight (Mon-Fri 1700-0659 hours) & $13.8(12.3-15.2)$ & $14.6(12.7-16.4)$ & $15.4(12.8-18.0)$ & $14.3(13.3-15.3)$ \\
\hline Weekend-day (Sat, Sun 0700-1659 hours) & $12.7(11.3-14.1)$ & $10.9(9.3-12.5)$ & $12.8(10.4-15.2)$ & $12.1(11.2-13.1)$ \\
\hline Weekend-night (Sat, Sun 1700-0659 hours) & $32.6(30.7-34.6)$ & $24.9(22.6-27.1)$ & $32.7(29.4-36.1)$ & $30.1(28.7-31.4)$ \\
\hline Weekend (Fri 1700-Mon 0659 hours) & $32.6(30.6-34.5)$ & $30.5(28.1-32.9)$ & $35.2(31.8-38.7)$ & $32.3(31.0-33.7)$ \\
\hline \multicolumn{5}{|l|}{ Procedure recorded during visitc } \\
\hline X-ray, thoracic cavity without contrast & $21.3(19.6-23.0)$ & $12.3(10.6-14.0)$ & $35.9(32.5-39.3)$ & $22.3(21.1-23.5)$ \\
\hline Electrophysiological measurement (heart external application) & $9.6(8.4-10.8)$ & $3.5(2.5-4.4)$ & $8.6(6.6-10.6)$ & $8.3(7.5-9.1)$ \\
\hline X-ray, abdominal cavity without contrast & $6.6(5.6-7.6)$ & $4.2(3.1-5.2)$ & $5.2(3.6-6.8)$ & $5.9(5.2-6.6)$ \\
\hline X-ray, spinal vertebrae without contrast & $5.4(4.5-6.4)$ & $5.1(4.0-6.3)$ & $0.7(0.1-1.3)$ & $4.5(3.9-5.1)$ \\
\hline Drainage, bladder & $3.8(3.0-4.6)$ & $3.9(2.9-4.9)$ & $5.5(3.9-7.2)$ & $4.2(3.6-4.8)$ \\
\hline Specimen collection-blood & $4.1(3.3-5.0)$ & $2.1(1.4-2.9)$ & $5.7(4.0-7.3)$ & $4.1(3.5-4.6)$ \\
\hline \multicolumn{5}{|l|}{ Discharge location } \\
\hline Admitted & $26.0(24.2-27.9)$ & $6.4(5.2-7.7)$ & $31.3(27.9-34.6)$ & $20.5(19.3-21.7)$ \\
\hline Died & $0.4(0.1-0.7)$ & $0.1(0.1-0.2)$ & $0.1(0.1-0.4)$ & $0.2(0.1-0.4)$ \\
\hline Home & $58.7(56.7-60.8)$ & $80.9(78.9-83.0)$ & $60.1(56.6-63.6)$ & $66.3(64.9-67.6)$ \\
\hline Long-term care residence & $5.7(4.7-6.7)$ & $5.0(3.9-6.1)$ & $5.7(4.1-7.4)$ & $5.5(4.8-6.1)$ \\
\hline Other & $9.1(7.9-10.3)$ & $7.6(6.2-8.9)$ & $2.8(1.6-4.0)$ & $7.5(6.7-8.3)$ \\
\hline Died within 30 days of ED visit (if alive at discharge) & $3.0(2.3-3.7)$ & $0.6(0.2-1.0)$ & $4.4(2.9-5.9)$ & $2.5(2.0-2.9)$ \\
\hline
\end{tabular}

$\mathrm{Cl}$, confidence interval; CTAS, Canadian Triage Acuity Scale; ED, emergency department.

aCanadian Triage Acuity Scale measured at the time of ED intake registration.

bNumber of visits to ED.

'Top six most commonly reported procedures recorded during visit, denominator is all procedures. 
Table 4 Top five most common reasons for emergency department (ED) visits

Reason for visit

Frequency Percentage

(n)

(\%)

Potentially preventable $(N=752)$

Urinary tract infection (N390)

Pneumonia (J189)

Non-infective gastroenteritis and colitis (K529)

Cellulitis of lower limb/upper limb (L0311, L0310)

Chronic obstructive pulmonary disease with acute

exacerbation, unspecified (J441, J449)

Low acuity visits $(N=1443)$
Pain (M54, R52, M79, R10)

Persons encountering health services in other specified

153

142

10.6

circumstances $(Z 76)^{a}$

Fitting and adjustment of other devices $(Z 46)^{\mathrm{b}}$

Complications of genitourinary prosthetic devices (T83)

Decubitus ulcer (L89)

$\begin{array}{cr}385 & 51.2 \\ 91 & 12.1 \\ 42 & 5.6 \\ 30 & 4.0 \\ 26 & 3.4\end{array}$

High acuity visits $(\mathrm{N}=2208)$

Pain (R07, R10, M54)

Abnormalities of breathing (R06)

Functional intestinal disorders (K59)

Mental and behavioral disorders due to use of alcohol (F10)

Sepsis (A41)

Retention of urine (R33) $(N=2)$

bUrinary $(N=31)$, intestinal $(N=1)$, orthopedic $(N=1)$, other $(N=1)$.

Decreased access to primary care has been suggested to influence high ED utilization rates in other vulnerable populations with complex needs. ${ }^{25}$ The use of ED resources for preventable primary care conditions has implications for the coordination of care between that of ED physicians and primary care professionals. ${ }^{26}$ The fragmentation of care poses risks for duplicative treatment, misapplied treatment as well as cost-ineffective management. ${ }^{26}$

There are a few methodological limitations to this study. While the ACSC codes have been validated in the general population and for the geriatric population, these conditions have not been specifically validated in the context of TSCI as potentially preventable. For example, given the medical vulnerability of a person with tetraplegia, pneumonia may be less preventable than for the general population. Given the importance of understanding the role of primary care in the prevention and management of SHCs after TSCI this would be important future research. Due to limitations in available data, we were unable to stratify by neurological status and a longer-term follow-up was not possible. Additionally, there was greater variability in the rates of ED visits at the later time points post-injury due to decreasing sample size.

\section{CONCLUSIONS}

This is the first study that has examined ED utilization patterns and characteristics for persons with TSCI over an extended time period. Given the high prevalence of SHCs, and the high rates of ED use for low acuity and potentially preventable conditions, these results suggest that the ED is being used as an inappropriate substitute for primary health care for individuals with TSCI 50\% of the time.

\section{DATA ARCHIVING}

There were no data to deposit.

\section{CONFLICT OF INTEREST}

The authors declare no conflict of interest.

\section{ACKNOWLEDGEMENTS}

This work was supported by the Health System Performance Research Network (HSPRN) that receives funding from the Ministry of Health and Long-Term Care (MOHLTC) in Ontario. We also acknowledge the support of the Toronto Rehabilitation Institute, University Health Network, which receives funding under the Provincial Rehabilitation Research Program from the MOHLTC. The views expressed do not necessarily reflect those of the Ministry. Ms Guilcher's doctoral training has been supported throughout the years by the Canadian Institute for Health Research, Women's College Research Institute, Ontario Neurotrauma Foundation, Toronto Rehabilitation Institute, Community University Research Alliance, and Ontario Training Collaborative Program in Health Services and Policy Research. Dr Jaglal is the TRI Chair at the University of Toronto in Health Services Research.

1 World Health Organization. [homepage on the Internet]. c 2012 [cited May 2012] The World Health Report 2008: Primary Health Care Now More than Ever. World Health Organization: Geneva, 2008, Available from: http://www.who.int/whr/2008/whr08 en.pdf.

2 Chan BTB, Schull MJ, Schultz SE. Emergency department services in Ontario 1993-2000. Institute of Clinical Evaluative Sciences: Toronto, 2001.

3 Jaglal SB, Munce SE, Guilcher SJ, Couris CM, Fung K, Craven BC et al. Health system factors associated with rehospitalizations after traumatic spinal cord injury: a population-based study. Spinal Cord 2009; 47: 604-609.

4 Hitzig SL, Tonack M, Campbell KA, McGillivray CF, Boschen KA, Richards K et al. Secondary health complications in an aging Canadian spinal cord injury sample. Am J Phys Med Rehabil 2008; 87: 545-555.

5 Cardenas DD, Hoffman JM, Kirshblum S, McKinley W. Etiology and incidence of rehospitalization after traumatic spinal cord injury: a multicenter analysis. Arch Phys Med Rehab 2004: 85: 1757-1763.

6 Paker N, Soy D, Kesiktas N, Nur Bardak A, Erbil M, Ersoy S et al. Reasons for rehospitalization in patients with spinal cord injury: 5 years' experience. Int $J$ Rehab Res 2006; 29: 71-76.

7 DeVivo MJ, Whiteneck G, Go BK, Charles E. The Economic Impact of Spinal Cord Injury. Aspen Institute: Gaithersburg, MD, 1995.

8 Guilcher SJ, Munce SE, Couris CM, Fung K, Craven BC, Verrier M et al. Health care utilization in non-traumatic and traumatic spinal cord injury: a population-based study. Spinal Cord 2010; 48: 45-50.

9 DeVivo MJ, Yuying C, Mennemeyer ST, Deutch A. costs of care following spinal cord injury. Top Spinal Cord Inj Rehabil 2011; 16: 1-9.

10 Canadian Institute for Health Information [homepage on the Internet]. c1996-2012 [cited May 2012]. Final Report: The Canadian Enhancement of ICD-10. Available from: http://www.cihi.ca/ClHI-ext-portal/internet/en/document/standards + and + data + submission/standards/classification + and + coding/codingclass icd10.

11 Couris CM, Guilcher SJT, Munce SEP, Fung K, Craven BC, Verrier M et al. Characteristics of adults with incident traumatic spinal cord injury in Ontario, Canada. Spinal Cord 2010; 48: 39-44.

12 Deyo RA, Cherkin DC, Ciol MA. Adapting a clinical comorbidity index for use with ICD-9-CM administrative databases. J Clin Epidemiol 1992; 45: 613-619.

$13 \mathrm{Kralj}$ B. Measuring "rurality" for purposes of health-care planning: an empirical measure for Ontario. Ont Med Rev 2000; 67: 37-40.

14 Gruneir A, Bell CM, Bronskill SE, Schull M, Anderson GM, Rochon PA. Frequency and pattern of emergency department visits by long-term care residents-a populationbased study. J Am Geriatr Soc 2010; 58: 510-517.

15 Billings J, Zeitel L, Lukomnik J, Carey TS, Blank AE, Newman L. Impact of socioeconomic status on hospital use in New York City. Health Affairs (Millwood) 1993; 12: 162-173.

16 Canadian Institute for Health Information [homepage on the Internet]. c19962012 [cited May 2012]. Technical note: Ambulatory Care Sensitive Conditions. Available from: http://www.cihi.ca/cihi-ext-portal/internet/en/document/health + system + performance/indicators/health/tech acsc_2011.

17 Murray M, Bullard M, Grafstein ECTAS National Working Group, CEDIS National Working Group. Revisions to the Canadian emergency department triage and acuity scale implementation guidelines. Can J Emer Med Care 2004; 6: 421-427.

$18 \mathrm{Li} \mathrm{G}$, Lau JT, McCarthy ML, Schull MJ, Vermeulen M, Kelen GD. Emergency Department Utilization in the United States and Ontario, Canada. Acad Emerg Med 2007; 14: 582-584.

19 Canadian Institute for Health Information [homepage on the Internet]. c1996-2012 [cited May 2012]. Understanding Emergency Department Wait Times: Who is Using Emergency Departments and How Long Are They Waiting? Ottawa; 2005.. 
20 Chan TB, Schultz SE. Supply and Utilization of General Practitioner and Family Physician Services in Ontario. Institute for Clinical Evaluative Sciences: Toronto, 2005.

21 Glazier RH, Gozdyra P, Yeritsyan N. Geographic Access to Primary Care and Hospital Services for Rural and Northern Communities. Institute of Clinical Evaluative Sciences: Toronto, 2011.

22 DeJong G. Primary care for persons with disabilities: an overview of the problem. Am J Phys Med Rehab 1997; 76: S2-S8.

23 DeJong G, Hoffman J, Meade M, Bombardier C, Deutsch A, Nemunaitis G et al. Postrehabilitative health care for individuals with $\mathrm{SCl}$ : extending health care into the community. Top Spinal Cord Inj Rehabil 2011; 17: 46-58.

24 McColl MA, Forster D, Shortt SED, Hunter D, Dorland J, Godwin M et al. Physician experiences providing primary care to people with disabilities. Healthcare Policy 2008; 4: e129-e147.

\section{APPENDIX A}

International classification of disease, tenth revision, Canada (ICD10-CA), diagnostic codes for ambulatory sensitive conditions ${ }^{14}$

\begin{tabular}{|c|c|c|}
\hline Condition & $I C D-10-C A^{*}$ & Exclude \\
\hline Angina & $\begin{array}{l}\text { I20, } 123.82,124.0,124.8 \\
124.9\end{array}$ & $\begin{array}{l}\text { Cases with surgical procedure } \\
\text { (CCIt' } 1,2,5)\end{array}$ \\
\hline Asthma & $\mathrm{J} 45$ & \\
\hline $\begin{array}{l}\text { Acute } \\
\text { bronchitis }^{+}\end{array}$ & $\mathrm{J} 20$ & \\
\hline $\begin{array}{l}\text { Chronic obstruc- } \\
\text { tive pulmonary } \\
\text { disease }\end{array}$ & $\mathrm{J} 41, \mathrm{~J} 42, \mathrm{~J} 43, \mathrm{~J} 44, \mathrm{~J} 47$ & \\
\hline
\end{tabular}

Congestive heart $\quad 150, J 81$

Cases with surgical procedure failure and pul-

monary edema

Dehydration Diabetes mellitus

E86

E10.1, E10.6, E10.7,

E10.9, E11.0, E11.1,

E11.6, E11.7, E11.9,

E13.0, E13.1, E13.6,

E13.7, E13.9, E14.0,

E14.1, E14.6, E14.7, E14.9

Gastroenteritis K52

Grand mal seizure G40, G41

disorders

Hypertension I10.0, I10.1, I11

Hypoglycemia E162

Kidney or urinary N10, N151, N11, N136,

tract infection N390

Pneumonia $^{+} \quad$ J12, J13, J14, J15, J16, J18

Severe ear, nose $\mathrm{J} 02, \mathrm{~J} 03, \mathrm{~J} 312$

or throat infection

*ICD-10-CA = International Classification of Disease, Tenth Revision, Canada.

${ }^{+} \mathrm{CCl}=$ Canadian Classification of Health Interventions, a classification system for coding

health care procedures in Canada, used with ICD-10-CA.

+ Only when a secondary diagnosis of chronic obstructive disease is present. (CCI: 1.IJ.50, 1.IJ.57.GQ, 1.HZ.85, 1.IJ.76, 1.HB.53, 1.HD.53, 1.HZ.53, 1.HB.55, 1.HD.55, 1.HZ.55, 1.HB.54, 1.HD.54)

Cases with surgical procedure (CCI: 1.IJ.50, 1.IJ.57.GQ, 1.HZ.85, 1.IJ.76, 1.HB.53, 1.HD.53, 1.HZ.53, 1.HB.55, 1.HD.55, 1.HZ.55, 1.HB.54, 1.HD.54)
25 Weber EJ, Showstack JA, Hunt KA, Colby DC, Grimes B, Bacchetti P et al. Are the uninsured responsible for the increase in emergency department visits in the United States? Ann Emerg Med 2008; 52: 108-115.

26 Carrier E, Yee T, Holzwart RA. Coordination between emergency and primary care physicians. National Institute for Health Care Reform (Research Brief No. 3); 2011 Available from: http://www.nihcr.org/ED-Coordination.

This work is licensed under the Creative Commons Attribution-NonCommercial-No Derivative Works 3.0 Unported License. To view a copy of this license, visit http:// creativecommons.org/licenses/by-nc-nd/3.0/

\section{APPENDIX B}

Selection criteria

CD-10 Codes from Rick Hansen Foundation between FY 2003-FY 2009 (n=1515)

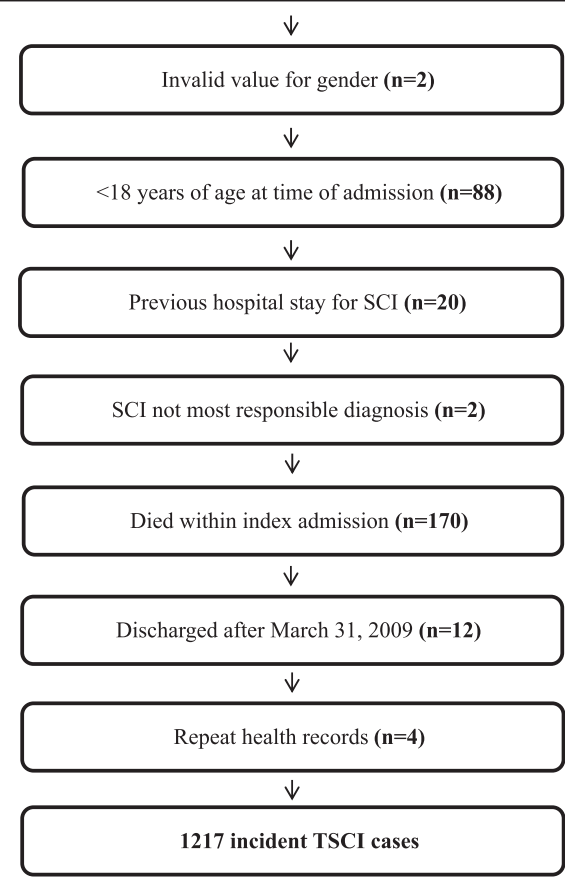

